\title{
Transparent conducting films
}

\author{
T P SHARMA and C P PANDEY ${ }^{\dagger *}$ \\ Department of Physics, Institute of Advanced Studies, Meerut University, Meerut 250005, \\ India \\ ${ }^{\dagger}$ Present address: Department of Physics, S.S. College, Shahjahanpur 242001, India \\ MS received 8 March 1984; revised 25 February 1985
}

\begin{abstract}
We present here a new technique, called vapour phase spray pyrolysis, for deposition of to and ITO films. Undoped to film showed semiconducting nature, a sheet resistance of $1088 \Omega / \square$, a donor ionization energy level of $40 \mathrm{meV}$, average visible transmittance of $75.4 \%$ and $n$-type conductivity. The indium doped (ITO) film $10 \mathrm{wt} \%$ showed metallic nature, a sheet resistance of $15 \Omega / \square$, average visible transmittance of $80-4 \%$ and $p$ type conductivity. Thus the ro and ro films showed fairly good electro-optical qualities, comparable to those obtained by sophisticated and costly techniques.
\end{abstract}

Keywords. Vapour phase spray pyrolysis; sheet resistance; impurity ionization energy: transmittance.

\section{Introduction}

Usually transparent conducting semiconductor oxide films are deposited by aqueous spray pyrolysis (Chopra et al 1982; Tomar and Garcia 1981) of soluble salts of the constituent atoms of the desired compounds onto the heated substrates, kept at a temperature of $450-500^{\circ} \mathrm{C}$. The deposition normally occurs through a hydrolysis reaction. We present here a technique different from that of aqueous spray pyrolysis. This technique may be called vapour phase spray pyrolysis as in this technique the vapours of the metals whose oxides are to be deposited are sprayed on heated substrates. To $\left(\mathrm{SnO}_{2}\right)$ and ro (indium doped $\mathrm{SnO}_{2}$ ) films were deposited on heated glass substrates. The films thus deposited showed good electrical conductivity and good visible transmittance.

\section{Experimental details}

The metal whose semiconducting oxide film is to be deposited is melted in a glass vessel as shown in figure 1 . The vessel height is $5 \mathrm{~cm}$ and its diameter $2 \mathrm{~cm}$, the nozzle neck and the nozzle are of $0.5 \mathrm{~cm}$ diameter. The temperature of the metal is the same as the temperature of the glass substrate which is kept between 250 and $300^{\circ} \mathrm{C}$. The vessel and the substrate are kept in fixed positions. Nascent chlorine gas produced by reaction of concentrated $\mathrm{HCl}$ with $\mathrm{KMnO}_{4}$, is mixed with vapours of molten tin to form stannic chloride. Vapours of $\mathrm{SnCl}_{4}$ falling on heated substrates are hydrolysed by atmospheric

\footnotetext{
* To whom all correspondence should be addressed.
} 


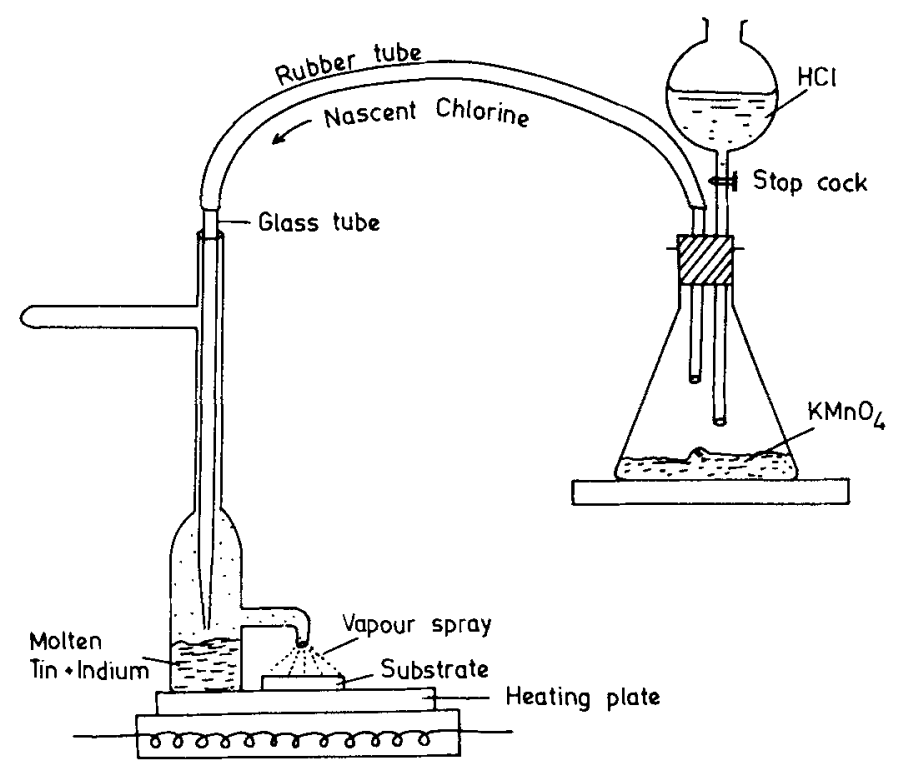

Figure 1. Experimental set up for vapour phase spray pyrolysis.

moisture and form a ro film on it. The reaction proceeds through the following steps,

$$
\begin{aligned}
2 \mathrm{KMnO}_{4}+16 \mathrm{HCl} \rightarrow & 2 \mathrm{KCl}+2 \mathrm{MnCl}_{2}+8 \mathrm{H}_{2} \mathrm{O}+10 \mathrm{Cl} \\
\mathrm{Sn}+4 \mathrm{Cl} \rightarrow \mathrm{SnCl}_{4} & \\
\mathrm{SnCl}_{4}+2 \mathrm{H}_{2} \mathrm{O} \rightarrow & \mathrm{SnO}_{2}+4 \mathrm{HCl}
\end{aligned}
$$

Indium doping is achieved through melting indium along with tin. Similar to tin, In reacts with nascent $\mathrm{Cl}$ and turns into $\mathrm{InCl}_{3}$ which after hydrolysis is transformed to $\mathrm{In}_{2} \mathrm{O}_{3}$, thus forming ITO films.

To and ITo films thus formed were studied for $I-V$ characteristics and temperature dependence of resistivity by the four point probe method. Transmittance of films was studied by Spectronic-20 spectrophotometer of Bausch and Laumb make. The transmittance of the glass substrate was excluded by using a blank glass slide as reference. Majority carriers of films were determined by hot probe experiments. ITo films of 2, 10 and $25 \mathrm{wt} \%$ indium were deposited. Conductivity increased on doping.

\section{Results and discussion}

\subsection{I-V characteristics}

Figure 2 shows the $I-V$ characteristics of to and $10 \mathrm{wt} \%$ indium doped $\mathrm{SnO}_{2}$ (ITO) films. The sheet resistance is calculated by the relation (Maissel and Glang 1970),

$$
R_{s}=4.532 \mathrm{~V} / \mathrm{I}
$$

From the slope of the $I-V$ characteristics for the ro film we get a sheet resistance of $R_{s}=1088 \Omega / \square$. The sheet resistance achieved by sophisticated techniques is $100-500 \Omega / \square$. For the ito film, we got a sheet resistance of $R_{s}=15 \Omega / \square$. The sheet 


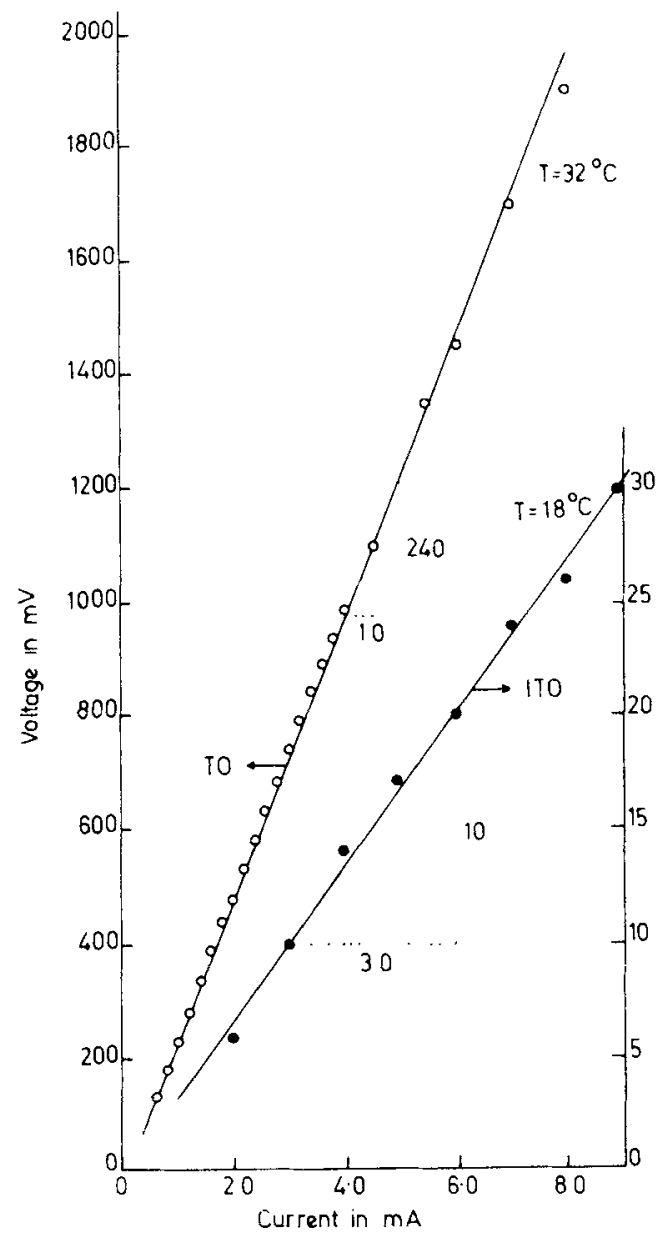

Figure 2. $I-V$ characteristics of to and ITO films.

resistance achieved by sophisticated techniques is $2-5 \Omega / \square$. The area of the uniform film was about 1 inch $^{2}\left(2.54 \mathrm{~cm}^{2}\right)$ and sheet resistance increased beyond this area.

\subsection{Temperature dependence of resistivity}

The temperature dependence of resistivity of the above ro and ro films is shown in figure 3. It shows that the resistivity of to film decreases with increasing temperature, i.e., it behaves as a semiconductor. From the temperature dependence of the semiconducting film, the ionization energy of the donor level can be determined. For a semiconducting film, the resistivity varies with temperature according to the relation

$$
\rho=a \exp \left[E_{i} / 2 k_{B} T\right]
$$

where $E_{\mathrm{i}}$ is the impurity ionization energy and $T$ is absolute temperature. From figure 3 for the ro film we get an impurity ionization energy level of $E_{i}=0.04 \mathrm{eV}$. This value is 


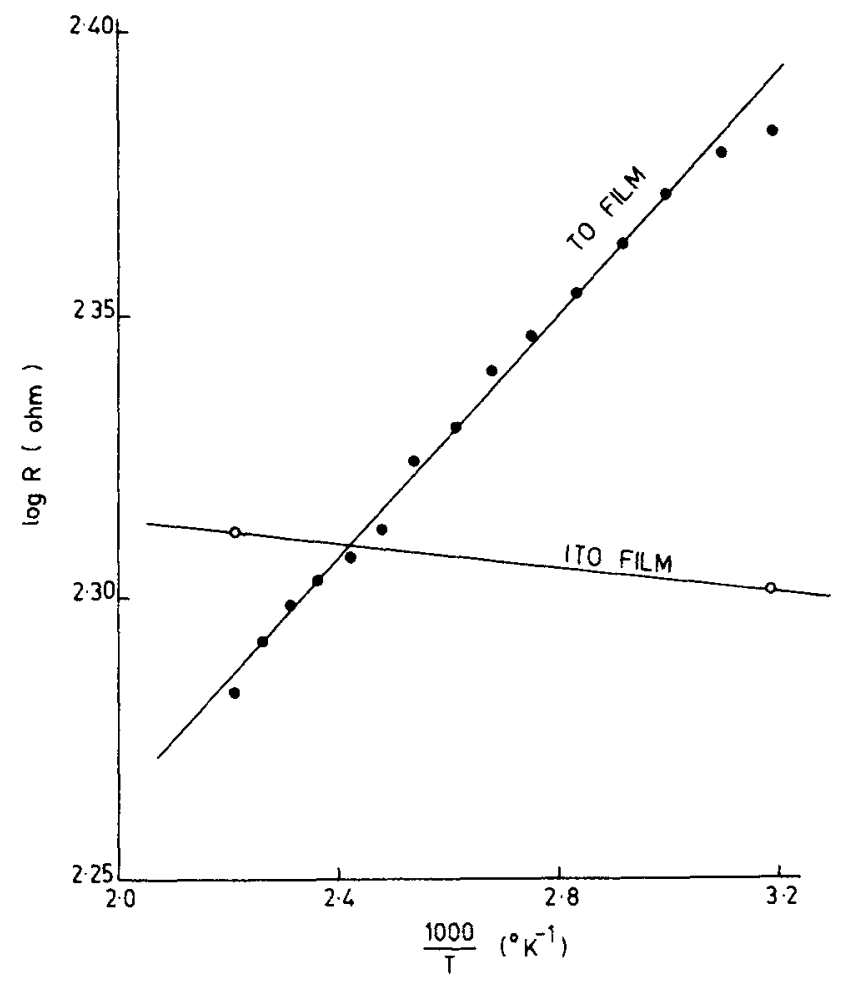

Figure 3. Temperature dependence of resistivity of to and rTo films.

in complete accord with the findings of Kozo Ishigiro et al (1958). They found it to lie between 0.01 to $0.04 \mathrm{eV}$ for low conductivity samples of ro films.

Figure 3 shows that the resistivity of the rTo film (slope enlarged 60 times) increases slowly with temperature. This shows the metallic nature of this film and therefore indicates the existence of considerable degenerate states in this film. This observation confirms the finding of Imai (1960).

\subsection{Transmittance of films}

The results of transmittance measurements in the wavelength range of $0-350$ to $0.950 \mu \mathrm{m}$ are shown in figure 4. This graph yields an average solar transmittance for the To and ITo films as $75.4 \%$ and $80.4 \%$ respectively. The maximum values attained for the best films are nearly $80 \%$ and $90 \%$ as reported by Chopra et al (1983).

The existence of interference peaks in transmission spectra shows that the films are fairly uniform as reported by Swanpoel (1983). In the case of a nonuniform or tapered film, the interference effects are destroyed and transmission is a smooth curve.

\subsection{Type of majority carriers of films}

All to films indicated $n$-type carriers and all ITo films indicated slightly $p$-type carriers. The $p$-type conduction of ITo films changed to $n$-type conduction on repeated heating 


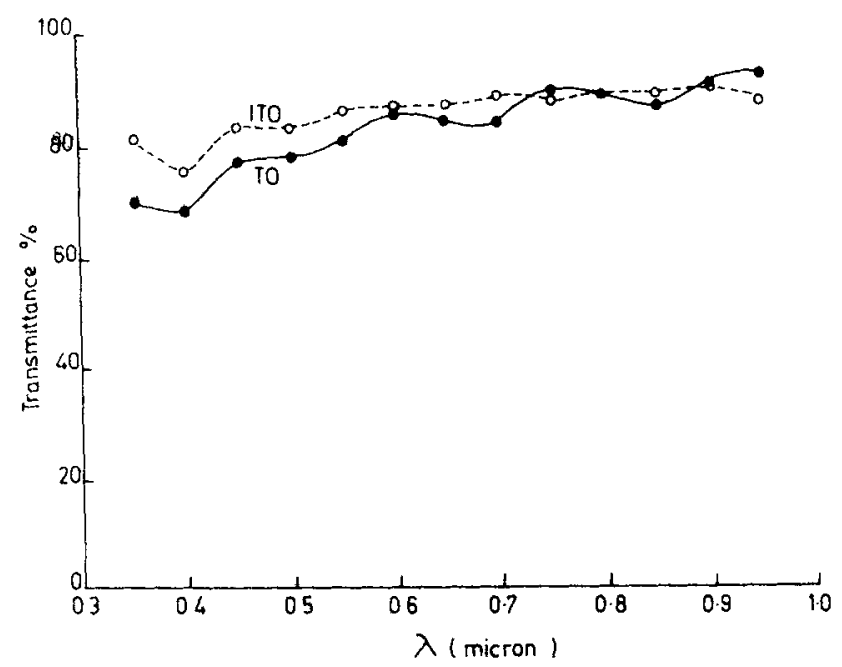

Figure 4. Transmittance of to and ITo films.

of films. This observation tallies with the findings of Spence (1967). This p-type conductivity is clearly attributable to the doping effect of indium, a metal of the third group.

\section{Conclusions}

With the simple technique of vapour phase spray pyrolysis good quality transparent conducting films can be prepared. By this method films can be deposited at comparatively lower temperatures than the traditional aqueous spray pyrolysis methods. This technique has the potential to be extended to other dopants and can be applied to large area coatings by the proper choice of deposition geometry.

\section{Acknowledgement}

One of the authors (CPP) is thankful to UGC, New Delhi for a fellowship.

\section{References}

Chopra K L, Kainthala R C, Pandya D K and Thakoor A P 1982 Phys. Thin Films 12167 Chopra K L, Major S and Pandya D K 1983 Thin Solid Films 1021

Imai I 1960 J. Phys. Soc. Jpn. 15937

Kozo Ishigiro et al 1958 J. Phys. Soc. Jpn. 13296

Maissel L 1 and Glang R (eds.) 1970 Handbook of thin film technology (New York: McGraw Hill) p. 13 Spence W 1967 J. Appl. Phys. 383767

Swanpoel R 1983 J. of Phys. E. 161214

Tomar M S and Garcia F J 1981 Prog. Cryst. Growth Charact. 4221 